\title{
A Simple and Multiplex Loop-Mediated Isothermal Amplification (LAMP) Assay for Rapid Detection of SARS-CoV
}

\author{
Jin Hwa Kim ${ }^{1, \dagger}$, Minhee Kang $\mathbb{D}^{1,2, \dagger, *}$, Eunkyoung Park ${ }^{1,2}$, Doo Ryeon Chung $\mathbb{D}^{3,4,5, *}$, \\ Jiyeon Kim ${ }^{6,7}$ \& Eung Soo Hwang ${ }^{6,7}$
}

Received: 15 July, 2019 / Accepted: 23 August, 2019 / Published online: 11 November, 2019

(C) The Korean BioChip Society and Springer 2019

\begin{abstract}
The current diagnosis of severe acute respiratory syndrome-associated coronavirus (SARS$\mathrm{CoV}$ ) relies on laboratory-based tests since its clinical features are nonspecific, unlike other respiratory pathogens. Therefore, the development of a rapid and simple method for on-site detection of SARS-CoV is crucial for the identification and prevention of future SARS outbreaks. In this study, a simple colorimetric and multiplex loop-mediated isothermal amplification (LAMP) assay was developed to rapid screening of severe acute respiratory syndrome-associated coronavirus (SARS-CoV). It can be visually detected based on color change and monitored in real-time with fluorescent signals. The performance of this assay, based on six primers targeting open reading frame (ORF1b)
\end{abstract}

\footnotetext{
${ }^{1}$ Biomedical Engineering Research Center, Smart Healthcare Research Institute, Samsung Medical Center, Sungkyunkwan University School of Medicine, Seoul, Republic of Korea

${ }^{2}$ Department of Medical Device Management and Research, SAIHST, Sungkyunkwan University, Seoul, Republic of Korea

${ }^{3}$ Center for Infection Prevention and Control, Samsung Medical Center, Seoul, Republic of Korea

${ }^{4}$ Asia Pacific Foundation for Infectious Diseases (APFID), Seoul, Republic of Korea

${ }^{5}$ Division of Infectious Diseases, Department of Internal Medicine, Samsung Medical Center, Sungkyunkwan University School of Medicine, Seoul, Republic of Korea

${ }^{6}$ Department of Microbiology and Immunology, Seoul National University College of Medicine, Seoul, South Korea

${ }^{7}$ Institute of Endemic Diseases, Seoul National University Medical Research Center, Seoul, South Korea

'These authors contrilbuted equally.

*Correspondence and requests for materials should be addressed to

M.H. Kang ( $\square$ minhee.kang@samsung.com) and

D.R. Chung( $\bowtie$ minikang@skku.edu)
}

and nucleocapsid $(\mathrm{N})$ genes located in different regions of the SARS-CoV, was compared with real-time RT-PCR assay using various concentrations of target genes. The detection limit of the LAMP assay was comparable to that of real-time RT-PCR assay and therefore a few target RNA to $10^{4}-10^{5}$ copies could be detected within a short period of time (20-25 min). In addition, we established a multiplex real-time LAMP assay to simultaneously detect two target regions within the SARS-CoV genome. Two target sequences were amplified by specific primers in the same reaction tube and revealed that it was able to detect down to $10^{5}$ copies. The standard curve had a linear relationship with similar amplification efficiencies. The LAMP assay results in shorter "sample-to-answer" time than conventional PCR method. Therefore, it is suitable not only for diagnosis of clinical test, but also for surveillance of SARS virus in developing countries.

Keywords: SARS-CoV, Loop-mediated isothermal amplification, Colorimetric detection, Point-of-care test

\section{Introduction}

Severe acute respiratory syndrome (SARS) caused by a novel coronavirus $(\mathrm{CoV})$ is a highly contagious respiratory illness ${ }^{1}$. Its initial systemic symptoms include muscle pain, headache, and fever. Onset of respiratory symptoms such as cough, dyspnea, and pneumonia is then followed in $2 \sim 14$ days ${ }^{1,2}$. The SARS 
epidemic in July 2003 was one of the worst global epidemics. It affected 30 countries with 8,096 cases and 774 deaths $^{3-7}$. Since the end of its global epidemic, SARS has reemerged four times according to statistics of the World Health Organization (WHO): three times from laboratory accidents (Singapore and Taipei) and once in southern China where the source of infection remains undetermined although there is circumstantial evidence of animal-to-human transmission $^{8}$. Nevertheless, considering the recent outbreaks of SARS-like disease caused by the newly emerged Middle East respiratory syndrome (MERS-CoV) that is highly related to SARS-CoV ${ }^{9}$, the possibility of re-emergence of SARS may still remains ${ }^{10,11}$. Hence, the development of a rapid and simple method for on-site screening of SARS-CoV is important for the determination and prevention of future outbreaks. SARS-CoV could be detected at sera, throat washes and stool after the onset of illness with viral load ranging from $10^{4}$ to $10^{9}$ copies $/ \mathrm{ml}^{12}$ and the presence viral RNA differ from different anatomical site $^{13}$. Current diagnosis of SARS-CoV infection depends on laboratory-based tests (i.e., virus isolation in cell culture, serological, and molecular tests) because its clinical features are nonspecific particularly at the early stage of disease, unlike other respiratory illnesses. Virus isolation by inoculating cell cultures has long served as the gold standard to identify the presence of infection. However, this method needs considerable expertise and it is usually time consuming. Serological detection of viral antibodies (IgG, IgM) by enzyme linked immunosorbent assay (ELISA) and immunofluorescence (IFA) have been found to be sensitive $(98.2 \%$ for ELISA and $99.1 \%$ for the IFA; $33.6 \%$, respectively) ${ }^{14}$. However, antibodies are often undetectable in the first few days after the onset of infection, making early diagnosis difficult. On the other hand, conventional reverse transcriptase polymerase chain reactions (RT-PCR) and their quantitative approaches can allow direct detection of viral RNA. However, they require complex analytical instruments, expensive reagents, and considerable expertise $^{15}$. In addition, these techniques have limitations in developing countries and field situations because of poor resources and the lack of specialized personnel.

Loop-mediated isothermal amplification (LAMP) is a nucleotide acid amplification method that features high sensitivity, specificity, and rapidity under isothermal conditions ${ }^{16}$. LAMP requires a set of four specific primers that recognize six distinct sequences on the target. Primers used for LAMP assays contain a forward outer primer (F3), a backward outer primer (B3), a forward inner primer (FIP, comprised of two binding domains, F1c and F2), and a backward inner primer (BIP, comprised of two binding domains, B1 and B2c). FIP and BIP, of which both the $3^{\prime}$ region and $5^{\prime}$ region match the target, can interact with upstream external primers, resulting in the displacement of strands containing self-complementary regions that form stem-loop structures ${ }^{17}$. The reaction can be conspicuously accelerated by adding two loop primers (LF and LB), thus reducing the total reaction time ${ }^{18}$. Amplification products can be detected at the endpoint by using several methods, including gel electrophoresis, measuring turbidity derived from magnesium pyrophosphate precipitation ${ }^{19}$, and fluorescent signal generated by DNA intercalators such as calcein and SYBR green $\mathrm{I}^{20}$. LAMP does not need any special devices for processing. Thus, it is widely used for the detection of a wide range of pathogens such as bacteria ${ }^{21,22}$, parasites ${ }^{23}$, and viruses ${ }^{24,25}$ including SARS-CoV ${ }^{26,27}$. For instance, H. Thai et al. ${ }^{26}$. had been validated reverse transcription (RT) LAMP assay using SARS-positive clinical specimens with high sensitivity. By the way, in the detection method based on turbidity monitoring and DNA intercalators, the detection of unexpected signals derived from primer dimer and/or non-primer reactions can lead to false-positive results ${ }^{28}$. Apart from that, colorimetric detection methods using $\mathrm{pH}$ indicator dyes that monitor a significant $\mathrm{pH}$ change during LAMP amplification have been recently developed ${ }^{29}$. Its results can be simply and readily visualized with naked eyes based on color change. Recently, fluorescent RT-LAMP assays using quenching probes have also been developed to specifically monitor only primer-derived signals $^{30,31}$. However, most reported detection methods for LAMP are end-point techniques that can only detect a gene in a single reaction ${ }^{32,33}$. Multiplex LAMP assays that can detect and discriminate two or more target genes in a single reaction are limited.

In the present study, a simple colorimetric and multiplex loop-mediated isothermal amplification (LAMP) assay was developed to rapid screening of severe acute respiratory syndrome-associated coronavirus (SARS$\mathrm{CoV})$. The structural information of SARS-CoV and sequence alignment for LAMP assay are described in Figure 1. A set of primers comprising an inner pair (FIP, BIP), an outer pair (F3, B3), and a loop pair (LF, LB) and primer sequences for the open reading frame $1 \mathrm{~b}$ (ORF1b) and N (nucleocapsid) genes are lised in Table 1. We optimized, and validated our LAMP assay by color change and agarose gel electrophoresis. 
A

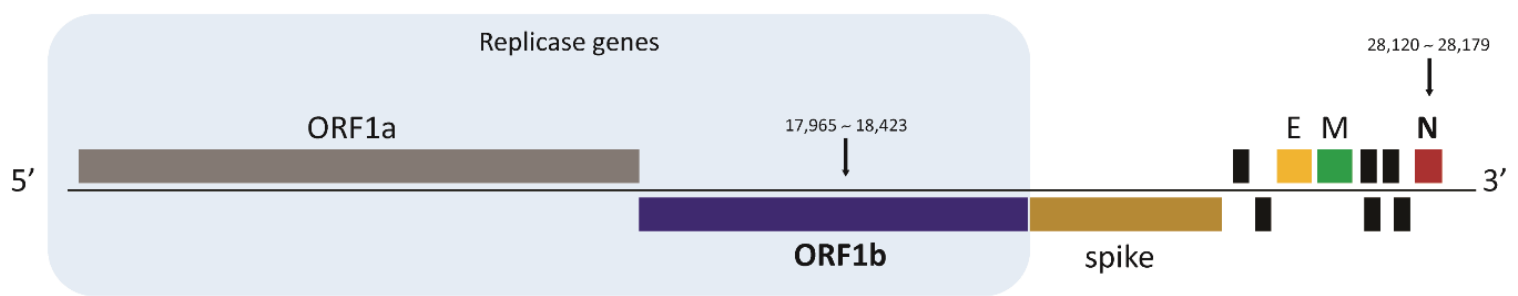

B GTGTTGACATACCAGGCATACCAAAGGACATGACCTACCGTAGACTCATCTCTATGATGG

GTTTCAAAATGAATTACCAAGTCAATGGTTACCCTAATATGTTTATCACCCGCGAAGAAGCTATTCGTC

Loop $F$
L1

ACGTTCGTGCGTGGATTGGCTTTGATGTAGAGGGCTGTCATGCAACTAGAGATGCTG

$\stackrel{\text { B1 }}{\stackrel{\text { TGGGTACTAACCTACCTCTCCAG CTAGGATTTTCTACAGGTGTTAACTTAGTAGC }}{\longrightarrow}}$

TGTACCGACTGGTTATGTTGACACTGAAAATAACACAGAATTCACCAGAGTTAATGCAA

AACCTCCACCAGGTGACCAGTTTAAACATCTTATACCAC

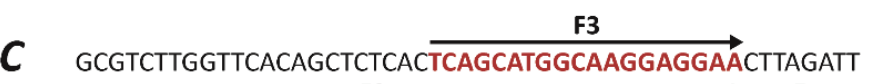

CCCTCGAGGCCAGGGCGTTCCAATCAACACCAATAGTGGTCCAGATGACCAAAT

TGGCTACTACCGAAGAGCTACCCGACGAGTTCGTGGTGGTGACGGCAA

TGGCTACTACCGAAGAGCTACCCGACGAGTTCGTGGTGGTGACGGCAA
Loop B

AATGAAAGAGCTCAGCCCCAGATGGTACTTCTATTACCTAGGAACTGGCCCAGAAGCTT

B3

CACTTCCCTACGGCGCTAACAAAGAAGGCATCGTATGGG

Figure 1. Structural information of SARS-CoV and sequence alignment for LAMP assay. A. Structure information of SARS-CoV (Genbank accession number: AY274119.3). Partial sequence was used for designing LAMP primers (ORF1b; 17,965 18,423, 459bp, N; 28,120 28,179, 600bp). B-C. Design of LAMP primers (B for ORF1b gene, C for N gene). Positions of designed primers are indicated by arrows.

Table 1. Primers used for LAMP assay.

\begin{tabular}{|c|c|c|}
\hline Primer & Sequence $\left(5^{\prime}-3^{\prime}\right)$ & $\begin{array}{l}\text { Length } \\
\text { (bp) }\end{array}$ \\
\hline ORF1b - F3 & CCAAGTCAATGGTTACCC & 18 \\
\hline ORF1b - B3 & ACTCTGGTGAATTCTGTG & 18 \\
\hline ORF $1 b-L F$ & AAGCCAATCCACGCACGAAC & 20 \\
\hline ORF1b-LB & TCTACAGGTGTTAACTTAGTAGC & 23 \\
\hline ORF1b-FIP* & [HEX]TGCAATGCAGCATCTCT[BHQ1-dT]AGTTGCATGACAGCGCGAAGAAGCTATTCGTC & 42 \\
\hline ORF1b - FIP & CAGCATCTCTAGTTGCATGACAGCGCGAAGAAGCTATTCGTC & 42 \\
\hline ORF1b-BIP & TGGGTACTAACCTACCTCTCCAGCAGTGTCAACATAACCAGTC & 43 \\
\hline $\mathrm{N}-\mathrm{F} 3$ & TCAGCATGGCAAGGAGGAA & 19 \\
\hline $\mathrm{N}-\mathrm{B} 3$ & TTAGCGCCGTAGGGAAGT & 18 \\
\hline $\mathrm{N}-\mathrm{LF}$ & ATTTGGTCATCTGGACCACT & 20 \\
\hline $\mathrm{N}-\mathrm{LB}$ & AGCCCCAGATGGTACTTCTA & 20 \\
\hline $\mathrm{N}-\mathrm{FIP}$ & CGTCGGGTAGCTCTTCGGTAGTCCAGGGCGTTCCAATCAAC & 41 \\
\hline $\mathrm{N}-$ FIP* & [FAM]TGCAATGCGTCGGGT[BHQ1-dT]AGCTCTTCGGTAGTCCAGGGCGTTCCAATCAAC & 41 \\
\hline $\mathrm{N}-\mathrm{BIP}$ & GTTCGTGGTGGTGACGGCAAGAAGCTTCTGGGCCAGTTC & 39 \\
\hline
\end{tabular}

In addition, performance of the LAMP assay was compared with real-time PCR assay using fluorescence- modified FIP primers. Finally, we also have established a multiplex LAMP assays that can be detected simultaneously two target regions in a single reaction. 


\section{Results and Discussion}

As a preliminary experiment, LAMP assays using either four or six primers targeting $\mathrm{N}$ gene of SARS$\mathrm{CoV}$ were performed. To determine the optimal reaction temperature, LAMP assay was conducted using a temperature gradient ranging from $50{ }^{\circ} \mathrm{C}$ to $72{ }^{\circ} \mathrm{C}$ for $30 \mathrm{~min}$. When the tube was examined before gel electrophoresis, a positive LAMP reaction was indicated by an orange color while negative reactions remained a color of pink (see Supplementary information S1 Figure). After tubes were visually assessed for color change, samples were subjected to agarose gel electrophoresis. Characteristic bands were evident in the gel if the product was present. Based on agarose gel electrophoresis, the reaction with four primers produced a detectable LAMP product at $62{ }^{\circ} \mathrm{C}$ (see Supplementary information $2 \mathrm{~S}$ Figure). However, nonspecific amplification occurred. For the reaction with six primers, amplifications occurred anywhere between $57{ }^{\circ} \mathrm{C}$ and $68^{\circ} \mathrm{C}$ for $\mathrm{N}$ gene and between $52{ }^{\circ} \mathrm{C}$

A

(a)

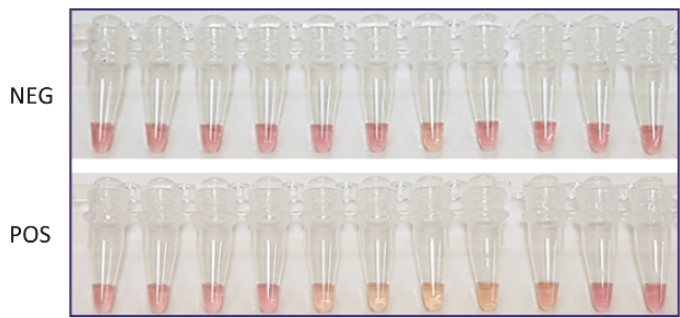

(b)

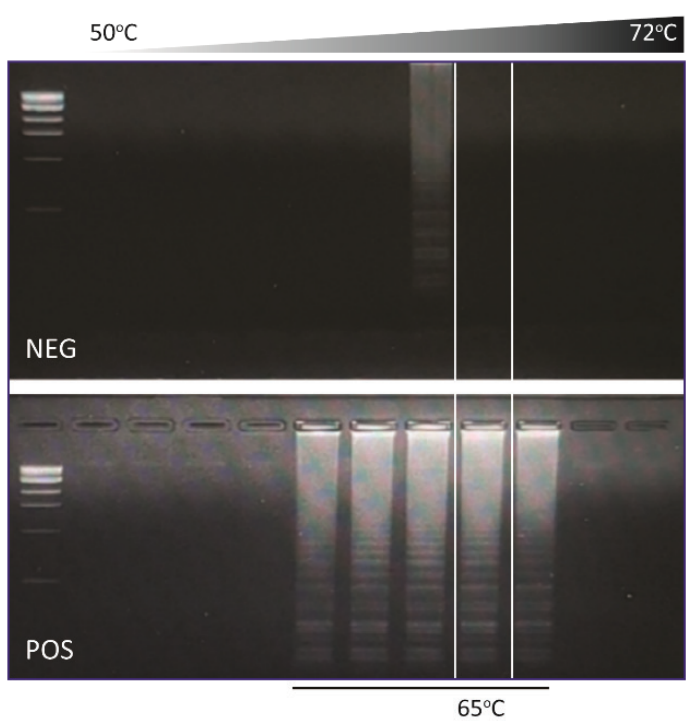

and $65{ }^{\circ} \mathrm{C}$ for ORF1b gene. Based on these results, all LAMP assays conducted later were performed using a mixture II containing loop primers LF and LB.

To confirm that our primer sets were suitable for LAMP analysis, gradient assay was performed using temperature from $50{ }^{\circ} \mathrm{C}$ to $72{ }^{\circ} \mathrm{C}$ with both cDNAs as templates. After reaction for 30 minutes, $20 \mu \mathrm{l}$ reaction containing cDNA showed color change from pink to yellow whereas the reaction containing distilled water as a negative sample did not show such color change. As a result of electrophoresis, smear band appeared at $62^{\circ} \mathrm{C}$ in a control containing only sterile water without a template. This non-specific amplification was attributed to sets of primers under certain assay conditions because LAMP relies on six different primers independently recognizing eight regions on the target sequences ${ }^{34}$. It is important therefore to determine optimal assay condition without nonspecific amplification associated with primers. In Figure 2, the reaction at $65^{\circ} \mathrm{C}$ of a control sample did not show a smear band. Therefore, the detection of

\section{B}

(a)

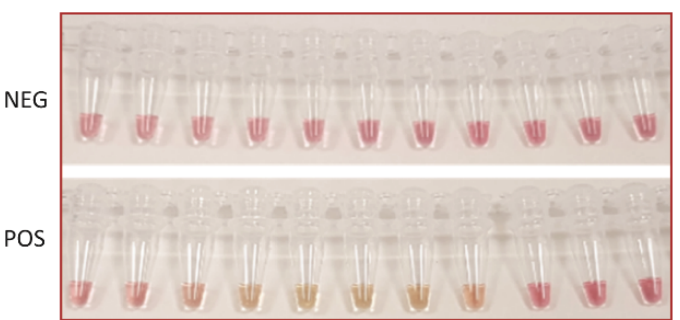

(b) $50^{\circ} \mathrm{C}$ $72^{\circ} \mathrm{C}$
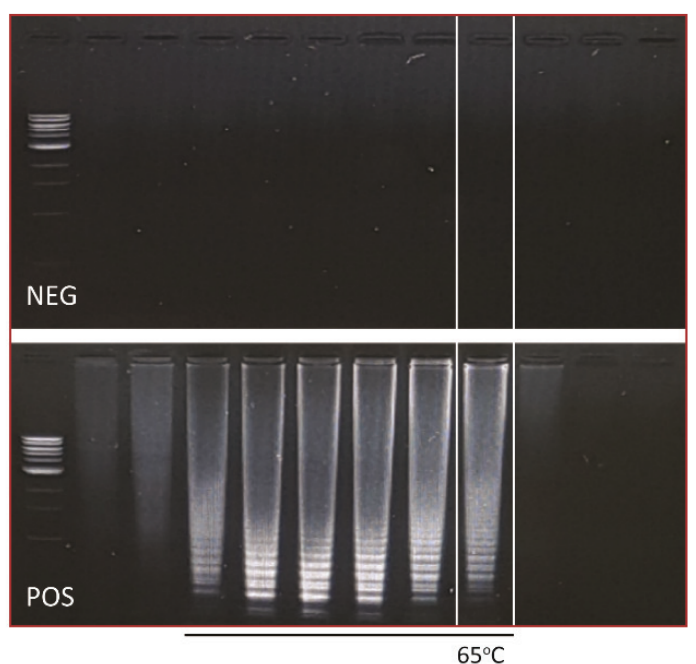

Figure 2. Optimization of LAMP assay. Detection of LAMP products. A, N gene; B, ORF1b gene (NEG, negative (non-template control, NTC); POS, positive with 50 ng of genomic DNA). (a) Naked eye detection at the end of assay (30 min). An orange color indicates a positive reaction and a neutral pink color indicates a negative reaction. (b) Agarose electrophoresis results of LAMP assay (temperature gradient from $50^{\circ} \mathrm{C}$ (lane 2) to $72^{\circ} \mathrm{C}$ (lane 11); lane $1,1 \mathrm{~kb}$ DNA ladder). The optimal temperature was determined to be $65^{\circ} \mathrm{C}$ for both targets. 
A

(a)

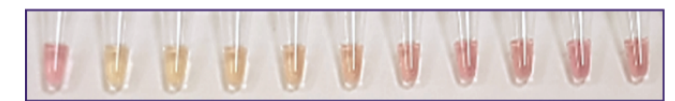

(b)

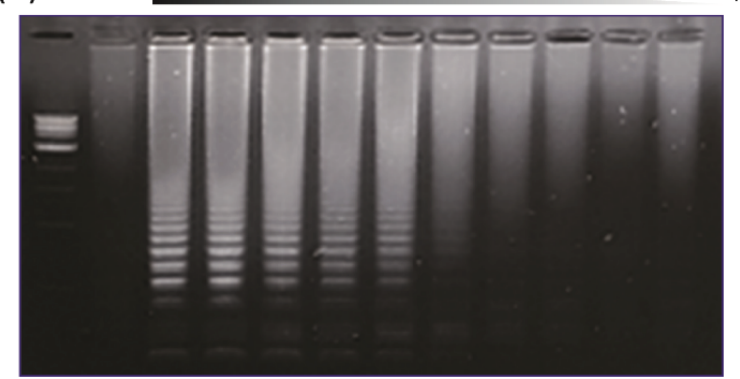

(c)

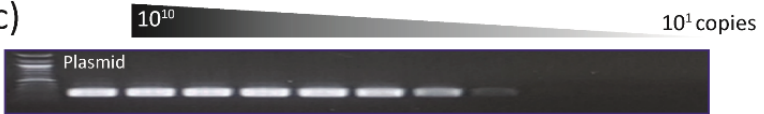

B

(a)

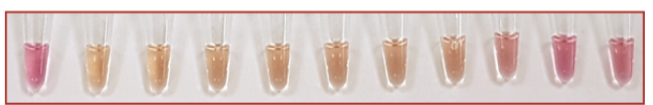

(b)

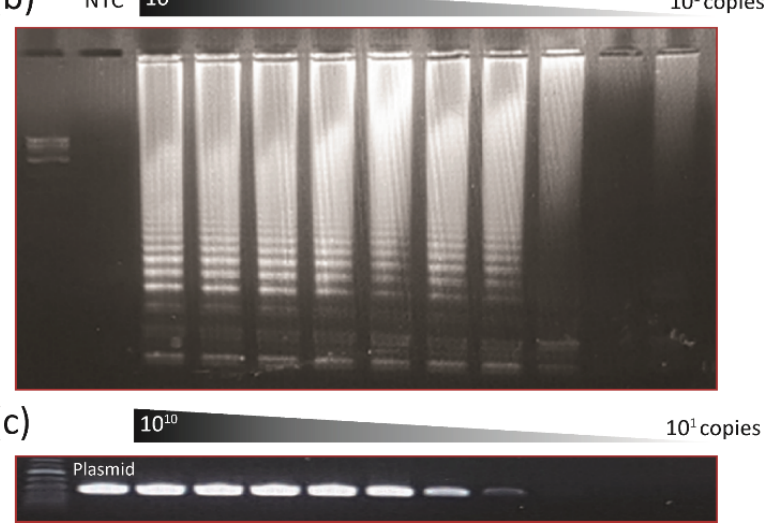

Figure 3. Sensitivity of LAMP assay. 10-fold serial dilution starting from $\sim 10^{10}$ copies of genomic DNA (lane 3 ) down to $\sim 10^{1}$ copies (lane 12). A, ORF1b gene (from $4.2 * 10^{10}$ to $4.2 * 10^{1}$ copies), and B N gene (from $3.2 * 10^{10}$ to $3.2 * 10^{1}$ copies); (a) Naked eye detection at the end of assay $(30 \mathrm{~min})$. An orange color indicates a positive reaction and a neutral pink color indicates a negative reaction. (b) Agarose electrophoresis results of LAMP assay (lane 1, 1kb DNA ladder; lane 2, non-template control (NTC)). The positive reaction shows a characteristic ladder of multiple bands in electrophoresis analysis. (c) Agarose electrophoresis results of RT-PCR assay (lane 1, 1kb DNA ladder; lane 2, $50 \mathrm{ng}$ of plasmid DNA).

ORF1b and N genes could be performed at this temperature. Sensitivities of LAMP and conventional PCR were then assessed by using 10-fold serial dilution of target $\left(10^{10} \sim 10^{1}\right.$ copies per reactions). The limit-ofdetection under optimal conditions (using six primers at $65{ }^{\circ} \mathrm{C}$ for $30 \mathrm{~min}$ ) are shown in Figure 3. Results of $1.5 \%$ agarose gel electrophoresis for ORF1b gene and $\mathrm{N}$ gene are shown in Figures 3A and 3B. The detection limit of LAMP assay was estimated to be $10^{5}$ copies per reaction for ORF $1 \mathrm{~b}$ gene and $10^{4}$ copies per reaction for $\mathrm{N}$ gene. This indicates that visual detection results are correlated with results from agarose gel electrophoresis. When the same amount of RNA was used in conventional RT-PCR, a similar level of amplification was observed. The detection limit of conventional RT-PCR was estimated to be about $10^{5}$ copies for ORF1b gene and $10^{4}$ copies for $\mathrm{N}$ gene.

The performance of real-time LAMP assay was also compared with that of real-time PCR assay (Figure 4). Real-time LAMP reaction was carried out at $65^{\circ} \mathrm{C}$ for $30 \mathrm{~min}$ and fluorescence signals were collected at $30 \mathrm{sec}$ intervals. During real-time LAMP reaction, fluorescence data were obtained from HEX channel for ORF1b gene and FAM channel for $\mathrm{N}$ gene. Threshold time $\left(T_{t}^{*}\right)$ was calculated as the time at which the fluorescence signal was equal to the threshold value. In the plot, the $\mathrm{Y}$-axis denotes fluorescence and the $\mathrm{X}$-axis shows time in minutes. Standard curves of LAMP assays were established. They were linear over at least five orders of magnitude $\left(\mathrm{R}^{2}>\right.$ 0.98 for ORF1b gene and $\mathrm{R}^{2}>0.99$ for $\mathrm{N}$ gene). Meanwhile, standard curves produced by real-time PCR revealed a good linearity within the detection limit, showing high correlations between $\mathrm{Ct}$ and DNA quantities $\left(\mathrm{R}^{2}>0.99\right.$ for both genes). The detection limit of the LAMP assay was slightly lower than or comparable to that of real-time PCR assay. However, target DNA with $10^{5}-10^{6}$ copies can be detected within a short period of time (20-25 $\mathrm{min})$.

Loop-mediated isothermal amplification (LAMP) assay is attractive for molecular diagnostic assays, especially for POC use. LAMP assay enables autocycling amplification under isothermal conditions within a short period of time without requiring expensive thermocycling equipment. In addition, its detection limit is comparable to that of conventional PCR. In this study, a LAMP assay was developed for rapid and quantitative detection of SARS-CoV. LAMP reaction performed at $65{ }^{\circ} \mathrm{C}$ within $30 \mathrm{~min}$ using six primers was able to detect up to $10^{5}$ copies. There were no significant differences between results obtained by using gel electrophoresis and those obtained by visual detection based on color. Additionally, real-time LAMP assay using fluorescence dye and their quencher decorated in either 5' end and internal of FIP primers were established and compared with real-time PCR assay. LAMP assay can detect 
A

(a)

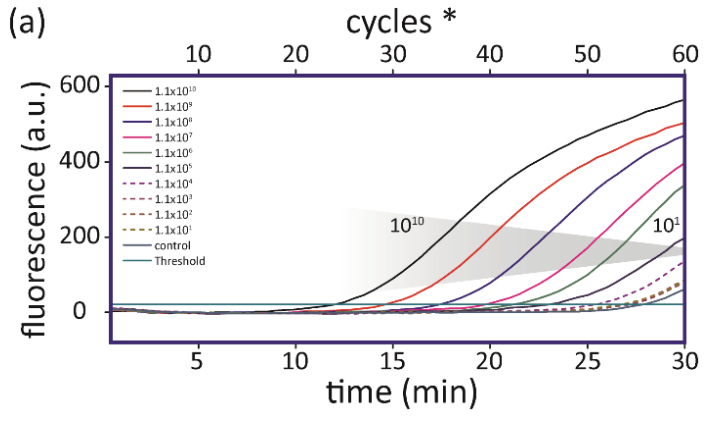

(b)

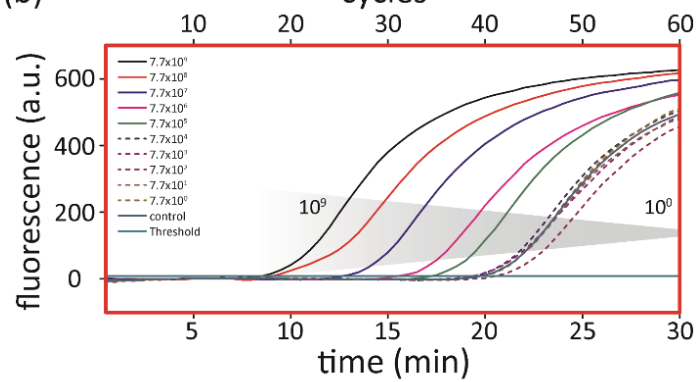

(c)

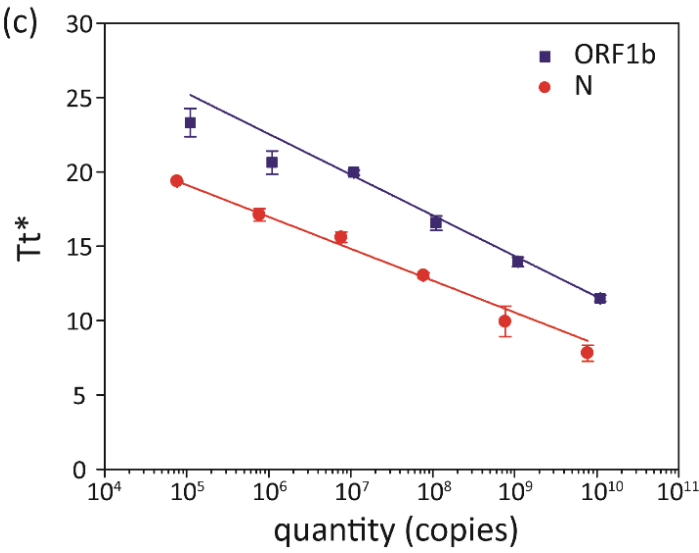

B

(a)

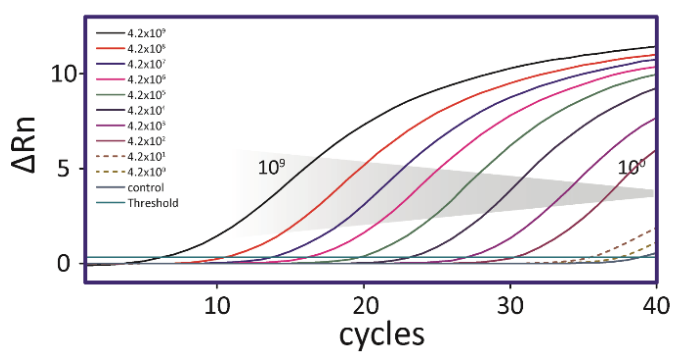

(b)

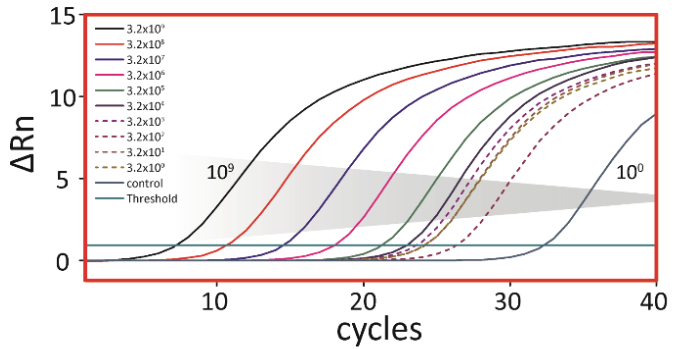

(c)

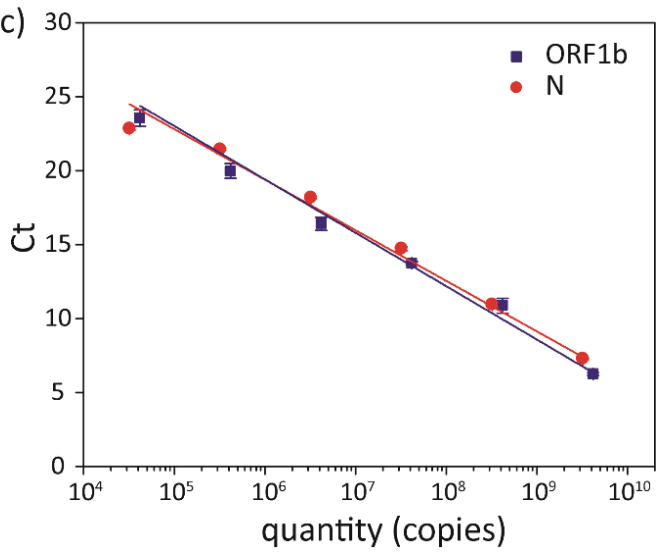

Figure 4. Sensitivity comparison of real-time LAMP and real-time RT-PCR assay using 10-fold serially diluted RNA containing about $10^{10}-10^{0}$ copies. A, Real-time LAMP assay, and B, Real-time RT-PCR assay. (a-b) Amplification plots for (a) ORF1b gene and (b) $\mathrm{N}$ gene. (c) Standard curve derived from amplification plots. The standard curve was generated using Log $\operatorname{lo}_{10}$-transformed concentrations of a 10-fold serially diluted RNA with corresponding threshold cycle $\left(\mathrm{C}_{t}\right)$ and threshold time $\left(\mathrm{T}_{t}{ }^{*}\right)$. Threshold time $\left(\mathrm{Tt}^{*}\right)$ represents the time at which the fluorescence was equal to the threshold value during LAMP cycles. Error bars represent standard deviations from triplicate reactions.

target RNA within a few minutes (20-25 min). Its limit of detection was $10^{5}$ copies, similar to real-time PCR.

On the other hand, multiplex assay is more attractive than performing multiple single-plex reactions. It also reduces the time and effort spent in the assay. In multiplex assay, two or more target sequences are simultaneously amplified in the same assay ${ }^{35}$. Complicating matters is that multiplex requires two or more sets of primers that do not interfere with each other in a single reaction. Since four or six primers are contained in a single LAMP reaction, optimization and validation of multiplex PCR need considerable time and effort. In this work, multiplex real-time LAMP assays have been validated as shown in Figure 5. Our multiplex LAMP assay with adjustment of primer concentration could detect down to $10^{5}$ copies based on RNA standards. The standard curve had a linear relationship $\left(\mathrm{R}^{2}>0.99\right)$ with similar amplification efficiencies. These results indicate that there is 
Table 2. Detection limit of Colorimetric, LAMP, and RT-PCR assays.

\begin{tabular}{cccccccccccc}
\hline \multirow{2}{*}{$\begin{array}{c}\text { Target } \\
\text { gene }\end{array}$} & Assay & \multicolumn{7}{c}{ Detection Copy Number (copies) } \\
\cline { 2 - 10 } & Colorimetric & $10^{10}$ & $10^{9}$ & $10^{8}$ & $10^{7}$ & $10^{6}$ & $10^{5}$ & $10^{4}$ & $10^{3}$ & $10^{2}$ & $10^{1}$ \\
\hline \multirow{2}{*}{ ORF1b } & LAMP & + & + & + & + & + & + & - & - & - & - \\
gene & RT-PCR & + & + & + & + & + & + & + & - & - & - \\
& Real-time LAMP & + & + & + & + & + & + & - & - & - & - \\
& qRT-PCR & + & + & + & + & + & + & - & - & - & - \\
\hline \multirow{2}{*}{ N gene } & Colorimetric & + & + & + & + & + & + & + & - & - & - \\
& LAMP & + & + & + & + & + & + & + & - & - & - \\
& RT-PCR & + & + & + & + & + & + & + & - & - & - \\
& Real-time LAMP & + & + & + & + & + & + & - & - & - & - \\
\hline
\end{tabular}

+, Amplification occurred; -, amplification did not occur.

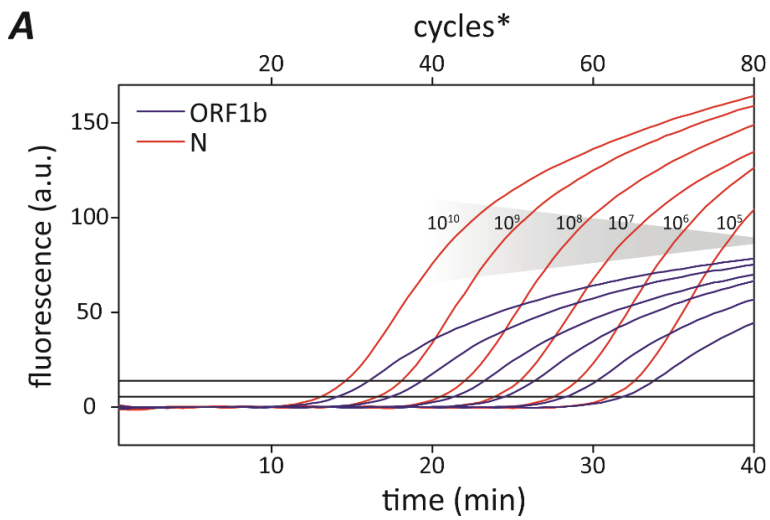

B

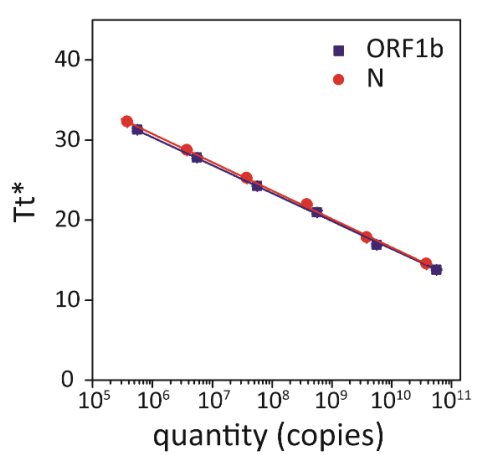

Figure 5. Multiplex capability of LAMP assay. Representative amplification plots and standard curves for 10-fold serially diluted RNA containing about $10^{10}-10^{5}$ copies of ORF $1 \mathrm{~b}$ gene and $\mathrm{N}$ gene. A Amplification plots and B standard curve derived from amplification plots. Threshold time $\left(\mathrm{T}_{\mathrm{t}}{ }^{*}\right)$ represents the time at which the fluorescence was equal to the threshold value during LAMP cycles. Error bars represent standard deviations from triplicate reactions. Multiplex LAMP assay could detect down to $10^{5}$ copies. The standard curve had a linear relationship $\left(\mathrm{R}^{2}>0.99\right)$ with similar amplification efficiencies. There was no amplification bias.

no preferential amplification of one target sequence over another (i.e., amplification bias) when equal primer concentrations were used.

\section{Conclusion}

In conclusion, a simple colorimetric LAMP assay for SARS-CoV was designed, optimized, and validated. We also demonstrate a multiplex LAMP assay in a single reaction for the specific detection of two target regions within the SARS-CoV genome. The LAMP assay has a shorter "sample-to-answer" time with detection performance comparable to conventional RTPCR. It can be easily adapted to different laboratory settings without expensive thermo-cycling equipment, particularly in developing countries.

\section{Materials and Methods}

\section{Virus Information}

We used nucleotide sequence of SARS-coronavirus Tor2 (accession number AY274119.3 from the NCBI nucleotide database) isolated from patients with severe acute respiratory syndrome (Figure 1A). Coronavirus $(\mathrm{CoV})$ genome is typically arranged in the order of 5, -polymerase (ORF1ab), spike (S), envelope (E), membrane (M), and nucleocapsid (N)-3' and short regions at both termini ${ }^{36,37}$. Generation of $\mathrm{CoV}$ full-length infectious cDNA clones has long been hampered due to the large size of the genome (around $30 \mathrm{~kb}$ ) and the instability of some $\mathrm{CoV}$ replicase gene sequences during its propagation in bacteria ${ }^{38}$. Therefore, partial SARS- 
$\mathrm{CoV}$ cDNAs were selected as target regions for amplification. (see Supplementary information 1S Table).

\section{Linearization and Extraction of Synthetic DNA}

Single-stranded DNA oligonucleotides covering target regions open reading frame (ORF1b) and nucleocapsid $(\mathrm{N})$ genes of SARS-CoV were cloned into pBIC-A vector (Bioneer Inc.) to be downstream of T7 promoter region for RNA transcription. Recombinant plasmid was linearized by digestion with BamHI and XhoI (New England Biolabs) for ORF1b and BamHI and Pcil (New England Biolabs) for N gene. These reactions were carried out with $20 \mu \mathrm{g}$ DNA, $5 \mu \mathrm{l}$ of 10X CutSmart buffer (New England Biolabs), and $3 \mu \mathrm{l}$ of an appropriately diluted BamHI and XhoI or BamHI and PciI. They were then incubated at $37{ }^{\circ} \mathrm{C}$ for 4 hours. Detected cDNA fragments were separated on $1 \%$ agarose gel and purified using Wiz$\operatorname{ard}{ }^{\circledR}$ DNA Clean-Up system (Promega).

\section{In Vitro RNA Transcription and cDNA Synthesis}

An in vitro RNA reverse transcription and DNA fragment removal were carried out using RiboMaxTM Large Scale RNA Production System (Promega) and T7 polymerase (Promega). Transcripts were produced in $20 \mu \mathrm{l}$ reaction buffer containing $1 \mu \mathrm{g}$ linearized DNA template, $10 \mu \mathrm{l} 2 \mathrm{x}$ RiboMAX express $\mathrm{T} 7$ buffer, $2 \mu 1 \mathrm{~T} 7$ polymerase, and nuclease-free water followed by incubation at $37^{\circ} \mathrm{C}$ for $30 \mathrm{~min}$. These transcripts were purified using RNase-Free DNase Set (Qiagen) which included DNase to remove unwanted DNA from RNA preparation according to the manufacturer's protocol. Total RNA was quantified by using ultraviolet (UV) spectroscopy (NanoDrop ND-1000, Wilmington). cDNA synthesis was performed with $100 \mathrm{ng}$ RNA and $20 \mathrm{pmol}$ of specific reverse primer incubated at $70^{\circ} \mathrm{C}$ for $5 \mathrm{~min}$ prior to reaction with 10 $\mu \mathrm{l}$ AccuPower ${ }^{\circledR}$ RT PreMix (Bioneer). For cDNA synthesis, the reaction was performed at $42{ }^{\circ} \mathrm{C}$ for 60 min and then incubated at $94{ }^{\circ} \mathrm{C}$ for $5 \mathrm{~min}$ for RTase inactivation. Total cDNA was quantified by ultraviolet (UV) spectroscopy (NanoDrop ND-1000, Wilmington). The copy number per $\mu$ l was calculated according to DNA/RNA Copy Number Calculator (http://www. endmemo.com/bio/dnacopynum.php). The concentration of the synthesized cDNA was $20 \mathrm{ng} / \mu \mathrm{l}$ as measured with a spectrophotometer, which corresponded to $4.2 * 10^{10}$ copies/ $\mu 1$ for ORF1b and $3.2 * 10^{10}$ copies $/ \mu \mathrm{l}$, and 10 -fold serial dilutions of the cDNA raging from copies were prepared. The synthesized cDNA were stored at $-70^{\circ} \mathrm{C}$.

\section{Design of Primer Sets for LAMP Reaction}

Primers for LAMP amplification targeting the open reading frame $1 \mathrm{~b}$ (ORF1b) and $\mathrm{N}$ (nucleocapsid) genes, respectively, were designed. A set of six primers corresponding to inner (FIP and BIP), outer (F3 and B3) primers, and internal loop primers (LF and $\mathrm{LB}$ ) were designed using Primer expression 4.0 (http://primer explorer.jp/e/). They included an inner pair (FIP, BIP), an outer pair (F3, B3), and a loop pair (LF, LB). Inner primers included a forward inner primer (FIP) consisting of a complementary sequence of $\mathrm{F} 1$ and a sense sequence of F2 and a backward inner primer (BIP) consisting of a complementary sequence B1 and a sense sequence of B2. Two outer primers included a forward outer primer (F3) and a backward outer primer (B3) for initiation of LAMP reaction. Internal loop primers (LF and LB) were designed to accelerate the reaction. Amplicon sizes of ORF1b and $\mathrm{N}$ genes were 214 and $207 \mathrm{bps}$, respectively. A pair of primers (named F3 and B3) were also used for RT-PCR to amplify target genes.

For real-time monitoring, fluorescence dye including FAM and HEX and their quencher dye (Black Hole Quencher ${ }^{\circledR)}$ were tagged in the 5' end and internal of FIP primers, respectively. Using each primer set containing modified FIP primers, real-time LAMP analysis was carried out with a Quantstudio 6 Flex Real-Time PCR system (Applied Biosystems). All primers were synthesized and purified by Bioneer. Sequence alignment and details of these primers with regard to their positions in genomic sequences are shown in Figures 1B and 1C and Table 1.

\section{LAMP Assay}

LAMP assay was performed with a WarmStart ${ }^{\circledR}$ LAMP 2X Master mix (New England Biolabs) according to the manufacturer's protocol. As a preliminary experiment, we compared two primer sets with or without loop primer and confirmed that the target was amplified more efficiently by the loop primer. Briefly, a LAMP reaction mixture $(20 \mu \mathrm{l})$ consisted of $10 \mu \mathrm{l}$ of $2 \mathrm{x}$ reaction mixture, $10 \mathrm{x}$ LAMP primer set (I or II), template (cDNA or RNA), and sterile water. The $10 \mathrm{x}$ LAMP Primer set I consisted of outer primers $\mathrm{F} 3$ and $\mathrm{B} 3(0.6 \mu \mathrm{M} / \mathrm{each})$ and inner primers FIP and BIP $(1.4 \mu \mathrm{M} / \mathrm{each})$. The $10 \mathrm{x}$ LAMP Primer set II consisted of outer primers F3 and B3 (0.2 $\mu \mathrm{M} /$ each), loop primers LF and LB $(0.4 \mu \mathrm{M} /$ each $)$, and inner primers FIB and BIP (1.6 $\mu \mathrm{M} /$ each). LAMP assays were performed with $10 \mu \mathrm{l}$ of $2 \mathrm{x}$ reaction mixture, $10 \times$ LAMP primer set, template (cDNA or 
RNA), $0.8 \mathrm{mmol} / \mathrm{L}$ FIP and modified FIP (FIP*), 1.6 $\mathrm{mmol} / \mathrm{L} \mathrm{BIP,} 0.8 \mathrm{mmol} / \mathrm{L}$ each of LF and LB primers, and $0.4 \mathrm{mmol} / \mathrm{L}$ each of $\mathrm{F} 3$ and $\mathrm{B} 3$ primers. Each reaction was performed with a thermal cycler (TaKaRa PCR Thermal Cycler Dice ${ }^{\circledR}$ Touch) under temperature control. Amplified products from the LAMP assay were analysed by electrophoresis with stained agarose gel as well as by naked eye using WarmStart $^{\circledR}$ Colorimetric LAMP 2X Master mix (New England Biolabs). Positive reaction showed a characteristic ladder of multiple bands in electrophoresis analysis and colour change from pink (prior to amplification) to yellow. All LAMP assays reported in this work were observed either by color change or agarose gel electrophoresis or both.

Real-time LAMP assay was carried out at $65{ }^{\circ} \mathrm{C}$ for 30 min using an QuantStudio 6 Flex Real-Time PCR System (Applied Biosystems) which was set to collect fluorescence signals at $30 \mathrm{~s}$ intervals. During real-time amplification, fluorescence data were obtained on HEX (ORF1b gene) or FAM (N gene) channel. Threshold time $\left(\mathrm{T}_{\mathrm{t}}{ }^{*}\right)$ was calculated as the time at which the fluorescence equaled the threshold value ${ }^{39}$.

\section{Optimization of LAMP Assay}

To determine the optimal reaction temperature, LAMP assay was conducted using cDNA of targets with a temperature gradient ranging from $50{ }^{\circ} \mathrm{C}$ to $72{ }^{\circ} \mathrm{C}$ for $30 \mathrm{~min}$. Amplified products from the LAMP assays were visualized by agarose gel electrophoresis and colour change.

\section{Sensitivity of LAMP Assay}

The sensitivity of LAMP assay compared to RT-PCR was assessed using 10-fold serially diluted purified genomic RNA, whose concentration ranging from $1.1 * 10^{10}$ copies to $1.1 * 10^{1}$ copies for ORF1b gene and from $7.7^{*} 10^{9}$ copies to $7.7^{*} 10^{1}$ copies for $\mathrm{N}$ gene. Non-template control (NTC, sterile water) was include in each LAMP run.

\section{RT-PCR Assay}

Primer pairs $\mathrm{F} 3$ and $\mathrm{B} 3$ for $\mathrm{N}$ gene (5'-TCAGCATG GCAAGGAGGAA-3', 5'-TTAGCGCCGTAGGGAA GT-3') and F3 and B3 for ORF1b gene (5'- CCAAGT CAATGGTTACCC-3', 5'- ACTCTGGTGAATTCTG TG-3') were used for RT-PCR. RT-PCR assays using ORF $1 \mathrm{~b}$ and $\mathrm{N}$ genes were also performed for detection using a RT-PCR kit (AccuPower® HotStart PCR PreMix) and a thermal cycler (Applied Biosystems) following manufacturers' protocols. Reactions were carried out in a total volume of $25 \mu \mathrm{L}$ containing PCR premix, 20 pmol of each primer, $1 \mu \mathrm{L}$ of template cDNA, and distilled water. Thermal cycling conditions consisted of an initial denaturation at $94{ }^{\circ} \mathrm{C}$ for $5 \mathrm{~min}$, followed by 40 cycles at $94{ }^{\circ} \mathrm{C}$ for $30 \mathrm{~s}$, annealing at $55^{\circ} \mathrm{C}$ for $30 \mathrm{~s}$, and extension at $72{ }^{\circ} \mathrm{C}$ for $30 \mathrm{~s}$. Reaction products were also subjected to $1.5 \%$ agarose gel electrophoresis followed by visualization. All PCR experiments were repeated at least three times.

Real time PCR reactions were performed in a QuantStudio 6 Flex Real-Time PCR System (Applied Biosystems) using Power SYBR PCR Master Mix (Applied Biosystems) under the same condition of RT-PCR. Standard curves were analysed by calculating the log of target DNA concentration against cycle threshold $(\mathrm{Ct})$ value. A standard curve was generated by using $\log 10$-transformed concentrations of 10 -fold serially diluted RNA and corresponding $\mathrm{Ct}$ value. Reactions were repeated at least three times.

Acknowledgements This research was supported by the government-wide R\&D Fund for the research of infectious diseases in Republic of Korea (HG18C 0062), and the Bio \& Medical Technology Development Program of the National Research Foundation (NRF) funded by the Ministry of Science (2016M3 A9B6919187, 2016M3A9B6919189).

Conflict of Interests The authors declare no competing financial interests.

\section{References}

1. Peiris, J.S.M., Lai, S.T., Poon, L.L.M., Guan,Y., Yam, L.Y.C., Lim, W., Nicholls, J., Yee, W.K.S., Yan, W.W., Cheung, M.T., Cheng, V.C.C., Chan, K.H., Tsang, D.N.C., Yung, R.W.H., Ng, T.K., Yuen, K.Y. \& Grp, S.S. Coronavirus as a possible cause of severe acute respiratory syndrome. Lancet Doi 10.1016/ S0140-6736(03)13077-2 (2003).

2. Tsang, K.W., Ho, P.L., Ooi, G.C., Yee, W.K., Wang, T., Chan-Yeung, M., Lam, W.K., Seto, W.H., Yam, L.Y., Cheung, T.M., Wong, P.C., Lam, B., Ip, M.S., Chan, J., Yuen, K.Y. \& Lai, K.N. A cluster of cases of severe acute respiratory syndrome in Hong Kong. N. Engl. J. Med. DOI 10.1056/NEJ Moa030666 (2003).

3. Kuiken, T., Fouchier, R.A.M., Schutten, M., Rimmelzwaan, G.F., van Amerongen, G., van Riel, D., Laman, J.D., de Jong, T., van Doornum, G., Lim, W., 
Ling, A.E., Chan, P.K.S., Tam, J.S., Zambon, M.C., Gopal, R., Drosten, C., van der Werf, S., Escriou, N., Manuguerra, J.C., Stohr, K., Peiris, J.S.M. \& Osterhaus, A. D.M.E. Newly discovered coronavirus as the primary cause of severe acute respiratory syndrome. Lancet DOI 10.1016/S0140-6736(03)13967-0 (2003).

4. Schlagenhauf, P. \& Ashraf, H. Severe acute respiratory syndrome spreads worldwide - WHO is frantically trying to find the source of the outbreaks and a cure for infected patients. Lancet DOI 10.1016/ S0140-6736(03)12843-7 (2003).

5. Kenneth, J. Severe Acute Respiratory Syndrome (SARS): The new epidemic. Natl. Med. J. India 16, 115-116 (2003).

6. Ksiazek, T.G., Erdman, D., Goldsmith, C.S., Zaki, S.R., Peret, T., Emery, S., Tong, S.X., Urbani, C., Comer, J.A., Lim, W., Rollin, P.E., Dowell, S.F., Ling, A.E., Humphrey, C.D., Shieh, W.J., Guarner, J., Paddock, C.D., Rota, P., Fields, B., DeRisi, J., Yang, J.Y., Cox, N., Hughes, J.M., LeDuc, J.W., Bellini, W.J., Anderson, L.J. \& Grp, S.W. A novel coronavirus associated with severe acute respiratory syndrome. N. Engl. J. Med. DOI 10.1056/NEJMoa 030781 (2003).

7. Summary of probable SARS cases with onset of illness from 1 November 2002 to 31 July 2003, $<$ https://www.who.int/csr/sars/country/table2004_04 $21 / \mathrm{en} />$

8. $\bar{S} A R S$ (Severe Acute Respiratory Syndrome), $<$ http://www.who.int/ith/diseases/sars/en/>

9. Chan, J.F.W., Lau, S.K.P., To, K.K.W., Cheng, V.C.C., Woo, P.C.Y. \& Yuen, K.Y. Middle East Respiratory Syndrome Coronavirus: Another Zoonotic Betacoronavirus Causing SARS-Like Disease. Clin. Microbiol. Rev. DOI 10.1128/Cmr.00102-14 (2015).

10. Gong, S.R. \& Bao, L.L. The battle against SARS and MERS coronaviruses: Reservoirs and Animal Models. A MEM DOI 10.1002/ame2.12017 (2018).

11. Cheng, V.C.C., Lau, S.K.P., Woo, P.C.Y. \& Yuen, K.Y. Severe acute respiratory syndrome coronavirus as an agent of emerging and reemerging infection. Clin. Microbiol. Rev. DOI 10.1128/Cmr.00023-07 (2007).

12. Wong, S.C., Chan, J.K., Lee, K.C., Lo, E.S. \& Tsang, D.N. Development of a quantitative assay for SARS coronavirus and correlation of GAPDH mRNA with SARS coronavirus in clinical specimens. J. Clin. Pathol. DOI 10.1136/jcp.2004.016592 (2005).

13. He, Z.P., Zhuang, H., Zhao, C.H., Dong, Q.M., Peng, G. \& Dwyer, D.E. Using patient-collected clinical samples and sera to detect and quantify the severe acute respiratory syndrome coronavirus (SARS-CoV). Virol. J. DOI 10.1186/1743-422X-4-32 (2007).

14. Wu, H.S., Chiu, S.C., Tseng, T.C., Lin, S.F., Lin, J.H.,
Hsu, Y.H., Wang, M.C., Lin, T.L., Yang, W.Z., Ferng, T.L., Huang, K.H., Hsu, L.C., Lee, L.L., Yang, J.Y., Chen, H.Y., Su, S.P., Yang, S.Y., Lin, S.Y., Lin, T.H. \& Su, I.S. Serologic and molecular biologic methods for SARS-associated coronavirus infection, Taiwan. Emerging Infect. Dis. DOI 10.3201/eid 1002.030731 (2004).

15. Wang, Y.Z., Yu, L., Kong, X.W. \& Sun, L.M. Application of nanodiagnostics in point-of-care tests for infectious diseases. Int. J. Nanomed., DOI 10.2147/ Ijn.S137338 (2017).

16. Notomi, T., Okayama, H., Masubuchi, H., Yonekawa, T., Watanabe, K., Amino, N. \& Hase, T. Loopmediated isothermal amplification of DNA. Nucleic Acids Res. 28, E63 (2000).

17. Tomlinson, J.A., Dickinson, M.J. \& Boonham, N. Detection of Botrytis cinerea by loop-mediated isothermal amplification. Lett. Appl. Microbiol. DOI 10.1111/j.1472-765X.2010.02949.x (2010).

18. Kubota, R., Vine, B.G., Alvarez, A.M. \& Jenkins, D.M. Detection of ralstonia solanacearum by loopmediated isothermal amplification. Phytopathology DOI 10.1094/PHYTO-98-9-1045 (2008).

19. Mori, Y., Nagamine, K., Tomita, N. \& Notomi, T. Detection of loop-mediated isothermal amplification reaction by turbidity derived from magnesium pyrophosphate formation. Biochem. Biophys. Res. Commun. DOI 10.1006/bbrc.2001.5921 (2001).

20. Iwamoto, T., Sonobe, T. \& Hayashi, K. Loop-mediated isothermal amplification for direct detection of Mycobacterium tuberculosis complex, M-avium, and M-intracellulare in sputum samples. J. Clin. Microbiol. DOI 10.1128/Jcm.41.6.2616-2622.2003 (2003).

21. Hill, J., Beriwal, S., Chandra, I., Paul, V.K., Kapil, A., Singh, T., Wadowsky, R.M., Singh, V., Goyal, A., Jahnukainen, T., Johnson, J.R., Tarr, P.I. \& Vats, A. Loop-mediated isothermal amplification assay for rapid detection of common strains of Escherichia coli. J. Clin. Microbiol. DOI 10.1128/Jcm.00152-08 (2008).

22. Zhou, Q.J., Wang, L., Chen, J., Wang, R.N., Shi, Y.H., Li, C.H., Zhang, D.M., Yan, X.J. \& Zhang, Y.J. Development and evaluation of a real-time fluorogenic loop-mediated isothermal amplification assay integrated on a microfluidic disc chip (on-chip LAMP) for rapid and simultaneous detection of ten pathogenic bacteria in aquatic animals. J. Microbiol. Methods DOI 10.1016/j.mimet.2014.06.008 (2014).

23. Kong, Q.M., Lu, S.H., Tong, Q.B., Lou, D., Chen, R., Zheng, B., Kumagai, T., Wen, L.Y., Ohta, N. \& Zhou, X.N. Loop-mediated isothermal amplification (LAMP): early detection of Toxoplasma gondii infection in mice. Parasites Vectors DOI 10.1186/17563305-5-2 (2012).

24. Kargar, M., Askari, A., Doosti, A. \& Ghorbani-Dalini, 
S. Loop-mediated isothermal amplification assay for rapid detection of hepatitis $\mathrm{C}$ virus. Indian J. Virol. DOI 10.1007/s13337-012-0067-2 (2012).

25. Yoneyama, T., Kiyohara, T., Shimasaki, N., Kobayashi, G., Ota, Y., Notomi, T., Totsuka, A. \& Wakita, T. Rapid and real-time detection of hepatitis A virus by reverse transcription loop-mediated isothermal amplification assay. J. Virol. Methods DOI 10.1016/ j.jviromet.2007.05.023 (2007).

26. Thai, H.T.C., Le, M.Q., Vuong, C.D., Parida, M., Minekawa, H., Notomi, T., Hasebe, F. \& Morita, K. Development and evaluation of a novel loop- mediated isothermal amplification method for rapid detection of severe acute respiratory syndrome coronavirus. J. Clin. Microbiol. DOI 10.1128/JCM.42.5. 1956-1961.2004 (2004).

27. Poon, L.L.M., Leung, C.S.W., Tashiro, M., Chan, K.H., Wong, B.W.Y., Yuen, K.Y., Guan, Y. \& Peiris, J.S.M. Rapid detection of the severe acute respiratory syndrome (SARS) coronavirus by a loopmediated isothermal amplification assay. Clin. Chem. DOI 10.1373/clinchem.2004.032011 (2004).

28. Njiru, Z.K. Loop-mediated isothermal amplification technology: towards point of care diagnostics. PLoS Neglected Trop. Dis. DOI 10.1371/journal.pntd.000 1572 (2012).

29. Poole, C.B., Ettwiller, L., Tanner, N.A., Evans, T.C., Wanji, S. \& Carlow, C.K.S. Genome filtering for new DNA biomarkers of Loa loa infection suitable for loop-mediated isothermal amplification. PLoS One DOI 10.1371/journal.pone.0139286 (2015).

30. Shirato, K., Semba, S., El-Kafrawy, S.A., Hassan, A.M., Tolah, A.M., Takayama, I., Kageyama, T., Notomi, T., Kamitani, W., Matsuyama, S. \& Azhar, E.I. Development of fluorescent reverse transcription loop-mediated isothermal amplification (RT-LAMP) using quenching probes for the detection of the Middle East respiratory syndrome coronavirus. $J$. Virol. Methods DOI 10.1016/j.jviromet.2018.05.006 (2018).

31. Viana, G.M.R., Silva-Flannery, L., Barbosa, D.R.L., Lucchi, N., do Valle, S.C.N., Ferias, S., Barbalho, N., Marchesini, P., Rossi, J.C.N., Udhayakumar, V., Povoa, M.M. \& de Oliveira, A.M. Field evaluation of a real time loop-mediated isothermal amplification assay (RealAmp) for malaria diagnosis in Cruzeiro do Sul, Acre, Brazil. PLoS One DOI 10.1371/journal. pone.0200492 (2018).

32. Sun, M.M., Liu, H., Huang, J.B., Peng, J.B., Fei, F.H., Zhang, Y., Hsiang, T. \& Zheng, L. A LoopMediated Isothermal Amplification Assay for Rapid Detection of Pectobacterium aroidearum that Causes
Soft Rot in Konjac. Int. J. Mol. Sci. DOI 10.3390/ ijms20081937 (2019).

33. Rahman, S.M.M., Song, H.B., Jin, Y., Oh, J.K., Lim, M.K., Hong, S.T. \& Choi, M.H. Application of a loop-mediated isothermal amplification (LAMP) assay targeting cox 1 gene for the detection of Clonorchis sinensis in human fecal samples. PLoS Neglected Trop. Dis. DOI 10.1371/journal.pntd.0005995 (2017).

34. Gadkar, V.J., Goldfarb, D.M., Gantt, S. \& Tilley, P.A.G. Real-time Detection and Monitoring of Loop Mediated Amplification (LAMP) Reaction Using Self-quenching and De-quenching Fluorogenic Probes. Sci. Rep. DOI 10.1038/s41598-018-23930-1 (2018).

35. Deng, H.W., Zhou, Y., Recker, R.R., Johnson, M.L. \& Li, J. Fragment size difference between multiplex and singleplex PCR products and their practical implications. Biotechniques DOI 10.2144/00292st05 (2000).

36. Lim, Y.X., Ng, Y.L., Tam, J.P. \& Liu, D.X. Human Coronaviruses: A Review of Virus-Host Interactions. Diseases DOI 10.3390/diseases4030026 (2016).

37. Marra, M.A., Jones, S.J.M., Astell, C.R., Holt, R.A., Brooks-Wilson, A., Butterfield, Y.S.N., Khattra, J., Asano, J.K., Barber, S.A., Chan, S.Y., Cloutier, A., Coughlin, S.M., Freeman, D., Girn, N., Griffith, O.L., Leach, S.R., Mayo, M., McDonald, H., Montgomery, S.B., Pandoh, P. K., Petrescu, A.S., Robertson, A.G., Schein, J.E., Siddiqui, A., Smailus, D.E., Stott, J.E., Yang, G.S., Plummer, F., Andonov, A., Artsob, H., Bastien, N., Bernard, K., Booth, T.F., Bowness, D., Czub, M., Drebot, M., Fernando, L., Flick, R., Garbutt, M., Gray, M., Grolla, A., Jones, S., Feldmann, H., Meyers, A., Kabani, A., Li, Y., Normand, S., Stroher, U., Tipples, G.A., Tyler, S., Vogrig, R., Ward, D., Watson, B., Brunham, R.C., Krajden, M., Petric, M., Skowronski, D.M., Upton, C. \& Roper, R.L. The genome sequence of the SARS-associated coronavirus. Science DOI 10.1126/science.1085953 (2003).

38. Almazan, F., Sola, I., Zuniga, S., Marquez-Jurado, S., Morales, L., Becares, M. \& Enjuanes, L. Coronavirus reverse genetic systems: infectious clones and replicons. Virus Res. DOI 10.1016/j.virusres.2014. 05.026 (2014).

39. Zhang, X., Zhang, H., Pu, J., Qi, Y., Yu, Q., Xie, Y. $\&$ Peng, J. Development of a real-time fluorescence loop-mediated isothermal amplification assay for rapid and quantitative detection of Fusarium oxysporum f. sp. cubense tropical race 4 in soil. PLoS One DOI 10.1371/journal.pone.0082841 (2013).

Copyright for the published papers belongs to the Korean BioChip Society. pISSN 1976-0280. eISSN 2092-7843. 